\title{
Genotyping of Streptococcus agalactiae (group B streptococci) isolated from vaginal and rectal swabs of women at 35-37 weeks of pregnancy
}

\author{
Nabil Abdullah El Aila ${ }^{\dagger 1}$, Inge Tency ${ }^{\dagger 2}$, Geert Claeys ${ }^{1}$, Bart Saerens ${ }^{1}$, Ellen De \\ Backer $^{1}$, Marleen Temmerman ${ }^{2}$, Rita Verhelst ${ }^{1}$ and Mario Vaneechoutte* ${ }^{1}$
}

Address: ${ }^{1}$ Laboratory Bacteriology Research, Department of Clinical Chemistry, Microbiology \& Immunology, University of Ghent, Ghent, Belgium and 2Department of Obstetrics \& Gynaecology, Ghent University Hospital, University of Ghent, Ghent, Belgium

Email: Nabil Abdullah El Aila - nabil.elaila@ugent.be; Inge Tency - Inge.Tency@UGent.be; Geert Claeys - Geert.Claeys@UGent.be; Bart Saerens - BartSaerens@gmail.com; Ellen De Backer - ellekendb@yahoo.com; Marleen Temmerman - Marleen.Temmerman@UGent.be; Rita Verhelst - Rita.Verhelst@UGent.be; Mario Vaneechoutte* - Mario.Vaneechoutte@UGent.be

* Corresponding author †Equal contributors

Published: II September 2009

BMC Infectious Diseases 2009, 9:153 doi:10.1/86/147/-2334-9-153
Received: 5 March 2009

Accepted: II September 2009

This article is available from: http://www.biomedcentral.com/I47I-2334/9//53

(C) 2009 El Aila et al; licensee BioMed Central Ltd.

This is an Open Access article distributed under the terms of the Creative Commons Attribution License (http://creativecommons.org/licenses/by/2.0), which permits unrestricted use, distribution, and reproduction in any medium, provided the original work is properly cited.

\begin{abstract}
Background: Group B streptococci (GBS), or Streptococcus agalactiae, are the leading bacterial cause of meningitis and bacterial sepsis in newborns. Here we compared different culture media for GBS detection and we compared the occurrence of different genotypes and serotypes of GBS isolates from the vagina and rectum.

Methods: Streptococcus agalactiae was cultured separately from both rectum and vagina, for a total of 150 pregnant women, i) directly onto Columbia CNA agar, or indirectly onto ii) Granada agar resp. iii) Columbia CNA agar, after overnight incubation in Lim broth.

Results: Thirty six women (24\%) were colonized by GBS. Of these, 19 harbored GBS in both rectum and vagina, 9 only in the vagina and 8 exclusively in the rectum. The combination of Lim broth and subculture on Granada agar was the only culture method that detected all GBS positive women. Using RAPD-analysis, a total of 66 genotypes could be established among the 118 isolates from 32 women for which fingerprinting was carried out. Up to 4 different genotypes in total (rectal + vaginal) were found for 4 women, one woman carried 3 different genotypes vaginally and 14 women carried two 2 different genotypes vaginally. Only two subjects were found to carry strains with the same genotype, although the serotype of both of these strains was different.

Eighteen of the 19 subjects with GBS at both sites had at least one vaginal and one rectal isolate with the same genotype.

We report the presence of two to four different genotypes in $22(61 \%)$ of the 36 GBS positive women and the presence of identical genotypes in both sites for all women but one.

Conclusion: The combination of Lim broth and subculture on Granada medium provide high sensitivity for GBS detection from vaginal and rectal swabs from pregnant women. We established a higher genotypic diversity per individual than other studies, with up to four different genotypes among a maximum of 6 isolates per individual picked. Still, 18 of the 19 women with GBS from both rectum and vagina had at least one isolate from each sampling site with the same genotype.
\end{abstract}




\section{Background}

Streptococcus agalactiae, group B Streptococcus (GBS), is a leading cause of neonatal morbidity and mortality in the US, Western Europe and Australia. Maternal carriage has been recognized as the most important risk factor for GBS neonatal infection [1,2] and indeed vertical transmission before or during delivery has been shown [3,4]. Motherto-child transmission may lead to neonatal infection in 1 to 2 infants per 1,000 live births [5] with mortality rates ranging from 10 to $20 \%$ [6]. Among pregnant women, the prevalence of colonization with GBS ranges from 3.2 to $36 \%$ [7-9]. Screening consists of obtaining vaginal and rectal specimens for culture at 35 to 37 weeks of gestation. Recently, several molecular techniques have been applied to study the genetic diversity of GBS, such as restriction fragment length polymorphism analysis (RFLP) [10], ribotyping [10,11], pulsed-field gel electrophoresis (PFGE) [3,12-17] multilocus enzyme electrophoresis (MLEE) [18] randomly amplification of polymorphic DNA-analysis (RAPD) $[9,19,20]$, amplified cps restriction polymorphism analysis [21] and multilocus sequence typing (MLST) [13,22-25].

To our knowledge, only one study [12], addressed the genotypic and serological diversity of GBS within individual women. Therefore, the aim of this study was to compare the genotypes of the GBS isolates from separate vaginal and rectal swabs using a simple genotypic approach (RAPD analysis with primer OPM1, followed by capillary electrophoresis) and also to study the correlation between serotype and genotype of the GBS isolates.

\section{Methods \\ Study design}

The study was approved by the research ethics committee (IRB protocol nr 2007/096) of Ghent University Hospital, Flanders, North region of Belgium, and all the women gave written informed consent. Between April and December 2007, 150 paired vaginal and rectal swabs were collected from pregnant women at 35 - 37 weeks of gestation.

\section{Collection and culture of specimens}

All specimens were collected using nylon flocked swabs that were submerged into $1 \mathrm{ml}$ of liquid Amies transport medium (eSwab, Copan Diagnostics, Brescia, It.). For rectal specimens, a swab was carefully inserted approximately $1.5-2 \mathrm{~cm}$ beyond the anal sphincter and then gently rotated to touch anal crypts.

Vaginal samples were collected by inserting a swab into the vagina. The swab was rolled round through 360 degrees against the vaginal wall at the midportion of the vault. At Ghent University Hospital, the routine GBSscreening of pregnant women is always performed during the prenatal consultation at 35-37 weeks' gestation. All study samples were collected by midwives and transported to the Laboratory of Bacteriology Research within 4 hours.

A total of $70 \mu \mathrm{l}$ from the Amies liquid transport medium of each of the vaginal and rectal swabs was seeded on Columbia CNA agar with 5\% sheep blood (Columbia CNA agar, Becton Dickinson, Erembodegem, Belgium) and $200 \mu \mathrm{l}$ was inoculated into $5 \mathrm{ml}$ of Lim Broth (ToddHewitt broth, $1 \%$ yeast extract, $15 \mu \mathrm{g}$ nalidixic acid $/ \mathrm{ml}$ and $10 \mu \mathrm{g}$ colistin/ml) (Lim Broth, Becton Dickinson) [26]. Both media are selective for Gram positive bacteria.

The Columbia CNA agar plates were incubated at $37^{\circ} \mathrm{C}$ in $5 \% \mathrm{CO}_{2}$ for $24-48 \mathrm{~h}$.

The Lim Broth was incubated aerobically at $37^{\circ} \mathrm{C}$ for 18 24 hours and then subcultured onto Granada agar (Becton Dickinson) [27] and onto Columbia CNA agar. Granada agar was incubated at $37^{\circ} \mathrm{C}$ in an anaerobic chamber (BugBox, LedTechno, Heusden-Zolder, B.) for 24-48 h and Columbia CNA agar was incubated at $37^{\circ} \mathrm{C}$ in $5 \%$ $\mathrm{CO}_{2}$ for $24-48 \mathrm{~h}$.

Granada agar was examined for yellow-orange pigment colonies that confirm the presence of GBS, whereas $\beta$ haemolytic and non-haemolytic colonies were picked from Columbia CNA agar for further identification as $S$. agalactiae by the CAMP test.

Identification of the isolates as Streptococcus agalactiae The isolates were identified as $S$. agalactiae by the following criteria: growth and orange pigment formation on Granada agar, positive for the CAMP test on blood agar and molecular identification by tDNA-PCR [28].

\section{Antibiotic susceptibility testing}

Fourty isolates of group B streptococci of 8 pregnant women were tested by disk diffusion for susceptibility to clindamycin and erythromycin Colonies taken from Trypticase Soy Agar (TSA) + 5\% sheep blood (Becton Dickinson) were suspended in $5 \mathrm{ml}$ of saline and the inoculum was adjusted to the turbidity of a $0.5 \mathrm{McF}$ arland standard. This suspension was streaked onto TSA $+5 \%$ sheep blood to obtain confluent growth, disks were added and the plates were incubated overnight at $37^{\circ} \mathrm{C}$ with $5 \% \mathrm{CO}_{2}$. Strains were considered resistant to clindamycin and erythromycin when the inhibition zones were less than 15 $\mathrm{mm}$.

\section{DNA-extraction from isolates}

DNA was extracted from cultured isolates by alkaline lysis as follows: One bacterial colony was suspended in $20 \mu \mathrm{l}$ of lysis buffer $(0.25 \%$ sodium dodecyl sulfate, $0.05 \mathrm{~N}$ 
$\mathrm{NaOH}$ ) and heated at $95^{\circ} \mathrm{C}$ for $15 \mathrm{~min}$. The cell lysate was diluted by adding $180 \mu \mathrm{l}$ of distilled water. The cell debris was spun down by centrifugation at $16,000 \mathrm{~g}$ for $5 \mathrm{~min}$. Supernatants were used for PCR or frozen at $-20^{\circ} \mathrm{C}$ until further use.

\section{Genotyping of isolates}

The cultured vaginal and rectal GBS isolates were genotyped using RAPD-analysis with the RAPD Ready-to-Go beads (GE Healthcare. Buckinghamshire, UK) as described previously [29] with primer OPM1 (5' GTT GGT GGC T) at a final concentration of $2 \mu \mathrm{M}$, including $0.2 \mu \mathrm{M}$ of fluorescent TET-labeled OPM1 primer. After $5 \mathrm{~min}$ at $94^{\circ} \mathrm{C}, 5 \mathrm{~min}$ at $35^{\circ} \mathrm{C}$ and $5 \mathrm{~min}$ at $72^{\circ} \mathrm{C}$, reaction mixtures were cycled 30 times in a Veriti ${ }^{\mathrm{TM}}$ Thermal Cycler (Applied Biosystems, Foster City, Ca.), with the following conditions: $30 \mathrm{~s}$ at $94^{\circ} \mathrm{C}, 1 \mathrm{~min}$ at $35^{\circ} \mathrm{C}$, and $1 \mathrm{~min}$ at $72^{\circ} \mathrm{C}$, with a final extension period of $5 \mathrm{~min}$ at $72^{\circ} \mathrm{C}$. Reaction vials were then cooled to $10^{\circ} \mathrm{C}$ and kept on ice until electrophoresis.

\section{Capillary electrophoresis}

A volume of $11.9 \mu \mathrm{l}$ of deionized formamide (ACE formamide, Lucron, De Pinte) was mixed with $0.6 \mu \mathrm{l}$ of an internal size standard mixture containing $0.3 \mu \mathrm{l}$ of the ROX400 high-density size standard (Applied Biosystems, Foster City, Ca.) and $0.3 \mu$ l of Map marker 1000 size standard (BioVentures, Murfreesboro, Tn.). One microliter of OPM1-PCR product was added. The mixtures were denatured by heating at $95^{\circ} \mathrm{C}$ for 3 min and placed directly on ice for at least $10 \mathrm{~min}$. Capillary electrophoresis was carried out using an ABI-Prism 310 genetic analyzer (Applied Biosystems) at $60^{\circ} \mathrm{C}$, at a constant voltage of $1.5 \mathrm{kV}$, and at a more or less constant current of approximately $10 \mathrm{~mA}$. Capillaries with a length of $47 \mathrm{~cm}$ and diameter of $50 \mu \mathrm{m}$ were filled with performance-optimized polymer 4 . Electropherograms were normalized using Genescan Analysis software, version 2.1 (Applied Biosystems).

\section{Data analysis}

OPM1-PCR fingerprints were obtained as table files from the Gene Scan Analysis software and used in a software program developed at our laboratory [30]. Using these sample files composed of numbers, representing the length of the amplification fragments in base pairs, a distance matrix was calculated with the in-house software using the differential basepairs ( $\mathrm{dbp}$ ) and the Dice algorithm [30]. Clustering analysis was done with the Phylip software http://evolution.genetics.washington.edu/ phylip.html, using the Neighbor Joining algorithm.

\section{Serotyping}

A total of 122 GBS isolates from 36 pregnant women were serotyped, using the latex co-agglutination kit of Essum $\mathrm{AB}$ (Umea, Sweden), according to the manufacturer's instructions. This kit enables to differentiate between serotypes Ia, Ib, II, III, IV and V.

\section{Statistical methods}

The McNemar test for correlated percentages was used to compare the sensitivity of the culture media.

\section{Results}

For a total of 150 women, culture was carried out separately for both rectal and vaginal sites, using three culture methods, i.e. directly onto Columbia CNA agar, or indirectly, by subculturing onto Columbia CNA agar resp. Granada agar, following overnight incubation in LIM broth.

\section{Comparison of culture techniques}

A total of 36 out of 150 pregnant women studied (24\%) were colonized by GBS. Of 55 samples from which GBS was isolated, 22 were positive by direct inoculation on Columbia CNA agar, 55 by Lim broth enrichment with subculture on Granada agar and 45 by Lim broth with subculture on Columbia CNA agar, resulting in sensitivities of 40, 100 and $81 \%$ respectively (Table 1).

Culture of vaginal specimens by direct plating on Columbia CNA agar was significantly less sensitive than culture in Lim broth with subculture on Granada agar or subculture on Columbia CNA agar (McNemar test, p < 0.0001). In addition, the culture of rectal specimens, direct plating onto Columbia CNA agar was significantly less sensitive than culture in Lim broth with subculture on Granada agar ( $\mathrm{p}<0.0001)$, which was more sensitive than culture on Lim broth with subculture on Columbia CNA agar ( $\mathrm{p}$ $=0.0313)$.

\begin{tabular}{|c|c|c|c|c|}
\hline \multirow[t]{2}{*}{ Specimen } & \multicolumn{4}{|c|}{ No. of positive GBS cultures detected by } \\
\hline & Columbia CNA agar & Lim broth + Granada agar & Lim broth + Columbia CNA agar & Total no. of women colonized \\
\hline Vaginal & 11 & 28 & 24 & 28 \\
\hline Rectal & 11 & 27 & 11 & 27 \\
\hline Total & 22 & 55 & 45 & 36 \\
\hline
\end{tabular}




\section{Carriage of GBS and genotyping}

For the 36 women that were found positive, 9 (25\%) carried GBS only in the vagina, $8(22 \%)$ only in the rectum and $19(53 \%)$ in both sampling sites (Table 1). Using three culture methods for two sampling sites, a maximum of 6 colonies per woman was picked, one from each of the positive culture plates. A total of 122 isolates were obtained (Table 2) of which 118 were genotyped using RAPD with primer OPM1 and analysis by capillary electrophoresis. The single isolates from four women were not fingerprinted, because there were no other isolates from the same subject to compare with. A tree was constructed after distance matrix calculation, and this revealed the presence of a total of 66 genotypes among the 118 isolates from 32 women for which fingerprinting was carried out. Only two subjects (RVS033 and RVS062) were found to carry strains of which the RAPD genotype was indistinguishable (Figure 1).

For 5 out of the 19 women from which both vaginal and rectal isolates were obtained, all the rectal and vaginal isolates were identical. For another 13 of these 19, at least one of the vaginal isolates had a similar genotype as one of the rectal isolates. Four women had two genotypes, seven had three genotypes and three had four genotypes. One of the five women with only rectal isolates had one genotype, whereas the other four had two genotypes. For the eight women with only vaginal isolates, four of them

Table 2: Overview of genotyping and serotyping results for 36 women positive for GBS.

\begin{tabular}{|c|c|c|c|c|c|c|c|}
\hline Number & Number & V DC & V LG & V LC & R DC & R LG & R LC \\
\hline 1 & RVSI43 & - & $+\mathrm{a} / \mathbf{V}^{\mathrm{b}}$ & - & - & - & - \\
\hline 2 & RVS038 & - & A/III & $\mathrm{A} / \mathbf{V}$ & - & - & - \\
\hline 3 & RVS07I & - & $A / I V$ & A/IV & - & - & - \\
\hline 4 & RVS073 & - & A/III & $\mathbf{A} / \mathbf{V}$ & - & - & - \\
\hline 5 & RVSI09 & - & $\mathrm{A} / \mathbf{V}$ & $A / \mathbf{V}$ & - & - & - \\
\hline 6 & RVS034 & A/III & B/lb & - & - & - & - \\
\hline 7 & RVS035 & B/III & A/II & A/II & - & - & - \\
\hline 8 & RVS076 & A/lb & B/lb & B/lb & - & - & - \\
\hline 9 & RVSI48 & - & A/III & B/III & - & - & - \\
\hline 10 & RVS004 & - & - & - & - & $+/ / \mathbf{a}$ & - \\
\hline 11 & RVS05I & - & - & - & - & $+/ \mathbf{V}$ & - \\
\hline 12 & RVS080 & - & - & - & - & $+/ I V$ & - \\
\hline 13 & RVS084 & - & - & - & - & A/NT & A/NT \\
\hline 14 & RVSO2I & - & - & - & B/la & A/lb & $\mathbf{A} / \mathbf{l b}$ \\
\hline 15 & RVS06I & - & - & - & $\mathrm{B} / \mathbf{V}$ & A/NT & A/NT \\
\hline 16 & RVSI 20 & - & - & - & - & $\mathbf{A} / \mathbf{l a}$ & B/la \\
\hline 17 & RVSI 45 & - & - & - & - & $A / l a$ & B/V \\
\hline 18 & RVSOI7 & - & $A / I V$ & $A / I V$ & - & $A / I V$ & \\
\hline 19 & RVS047 & - & $A / I V$ & A/IV & $A / I V$ & $A / I V$ & $A / I V$ \\
\hline 20 & RVSI06 & A/II & A/II & - & A/II & A/II & - \\
\hline 21 & RVSI 27 & $A / / V$ & A/IV & $A / I V$ & - & A/IV & $A / I V$ \\
\hline 22 & RVS069 & - & A/NT & - & - & A/NT & - \\
\hline 23 & RVS039 & - & $A / l a$ & $A / l a$ & - & B/la & $A / l a$ \\
\hline 24 & RVS083 & - & A/III & B/lb & A/IIII & A/IIII & A/IIII \\
\hline 25 & RVSII4 & - & B/V & $\mathbf{A} / \mathbf{V}$ & - & $\mathrm{A} / \mathbf{V}$ & $\mathbf{A} / \mathbf{V}$ \\
\hline 26 & RVSI 23 & - & A/NT & A/NT & - & A/NT & B/NT \\
\hline 27 & RVS027 & $\mathrm{A} / \mathbf{V}$ & $A / V$ & $\mathbf{C} / \mathbf{V}$ & $A / V$ & $\mathbf{A} / \mathbf{V}$ & $B / \mathbf{V}$ \\
\hline 28 & RVS033 & A/III & C/III & A/III & A/IIII & B/III & A/IIII \\
\hline 29 & RVS064 & A/III & B/III & A/III & A/III & C/III & A/III \\
\hline 30 & RVS075 & - & B/II & A/II & & C/II & A/II \\
\hline 31 & RVSIIO & $\mathbf{A} / \mathbf{V}$ & $\mathbf{A} / \mathbf{V}$ & $\mathbf{A} / \mathbf{V}$ & $C / V$ & B/V & $\mathbf{A} / \mathbf{V}$ \\
\hline 32 & RVSI 26 & A/NT & C/IV & A/NT & - & B/IV & A/NT \\
\hline 33 & RVSI36 & - & A/NT & B/IIII & - & A/NT & C/NT \\
\hline 34 & RVS03I & - & D/III & A/III & B/NT & A/III & C/II \\
\hline 35 & RVS062 & - & D/II & A/II & & B/II & C/II \\
\hline 36 & RVS074 & B/lb & A/lb & D/lb & B/lb & A/lb & $\mathrm{C} / \mathrm{lb}$ \\
\hline
\end{tabular}

Column headings: V DC: Vaginal sample, cultured directly on Columbia Agar, V LG: after Lim broth enrichment culture, plated onto Granada agar, V LC: after Lim broth enrichment culture, plated onto Columbia agar; R DC: Rectal sample, idem as for vaginal samples.

-: No GBS isolated.

a: Genotype: +: strain present, but not genotyped, A, B, C, D: genotypes numbered per individual.

b: Serotype: serotype number as determined by the Essum AB kit (Umea, Sweden). The following serotypes can be detected by this kit: la, lb, II, III, IV and V. NT: nontypeable. 


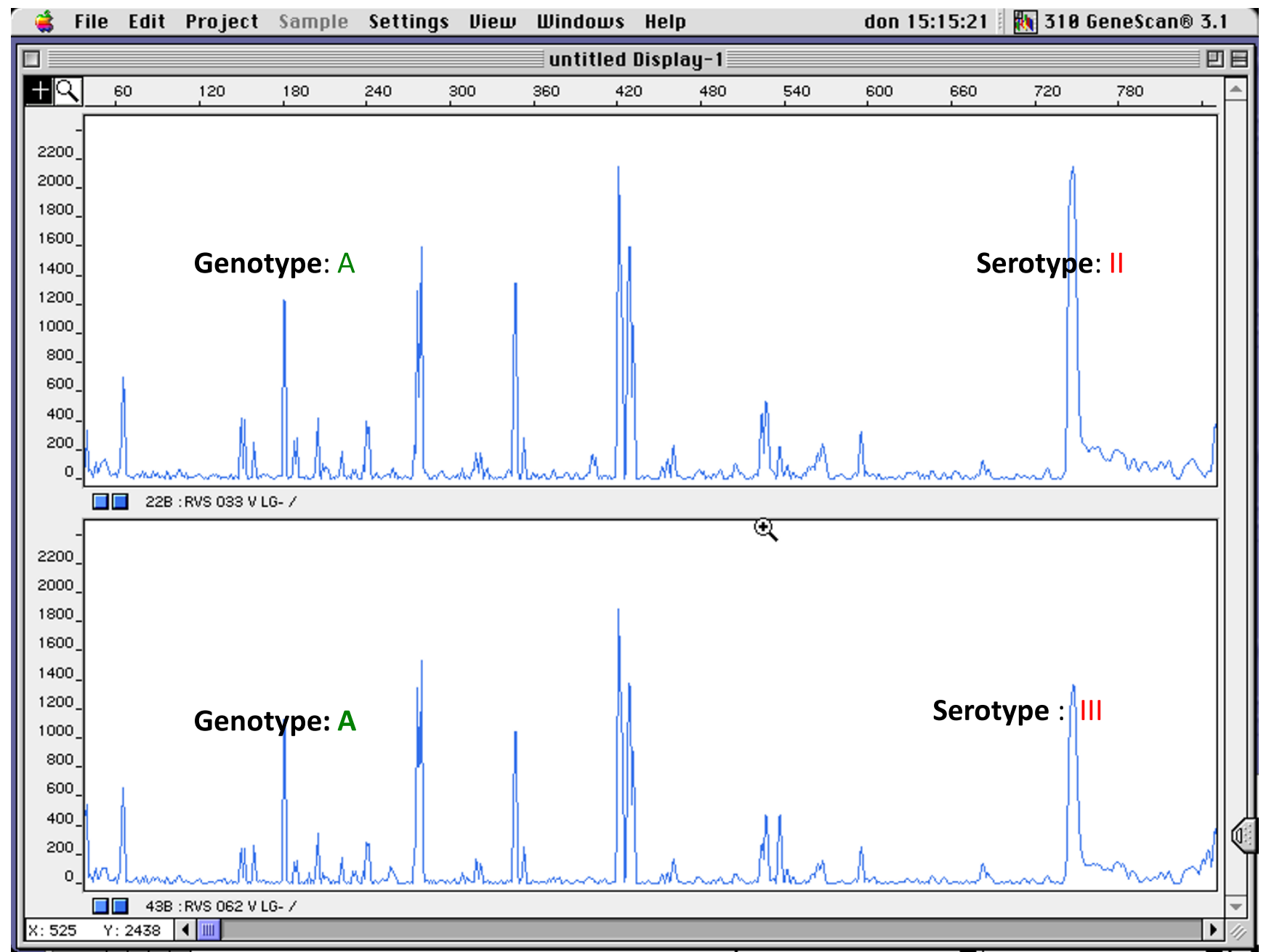

\section{Figure I}

Fingerprints of two isolates from two different subjects (RVS033 and RVS062) showing the same genotype and different serotypes. $x$-axis: length of amplified DNA fragments expressed in bps. $y$-axis: peak height (intensity of DNA-fragment).

had only one genotype and the other four had two genotypes.

\section{Serotyping}

In addition, all isolates were serotyped (Table 2). Seventeen isolates, from 7 subjects, were nontypeable. Furthermore, a rather equal distribution of the serotypes was found among the strains (Table 2). Eight women were found to carry isolates of the same genotype and serotype. An example is shown in Figure 2. In 11 subjects, only one serotype was present, although 2 to 4 genotypes could be found per subject. Nine subjects were found to carry isolates with different genotype and different serotype (Figure 3). The two isolates with the same genotype from the two different subjects belonged to different serotypes.
The frequency of different serotypes was as follows Ia: 10.4\%, Ib: 10.4\%, II: 10.4\%, III: 20.8\%, IV: 12.5, V: 20.8 and nontypeable: $14.5 \%$. Overall serotype distribution among vaginal vs rectal isolates was comparable, with a rectal predominance of Ia, i.e. 1 vaginal isolate vs 5 rectal isolates and a vaginal predominance of III, i.e. 10 vaginal isolates vs 4 rectal isolates. The presence of $L$. crispatus, generally accepted to confer vaginal colonisation resistance to pathogenic organisms $[31,32]$, did not seem to protect against vaginal $S$. agalactiae colonization, since a comparable number of women colonized only vaginally by $S$. agalactiae resp. only rectal by $S$. agalactiae were colonized vaginally by $L$. crispatus, i.e. $3 / 9$ resp. $2 / 8$. Six of the 19 women colonized by $S$. agalactiae both rectally and vaginally carried $L$. crispatus vaginally. 


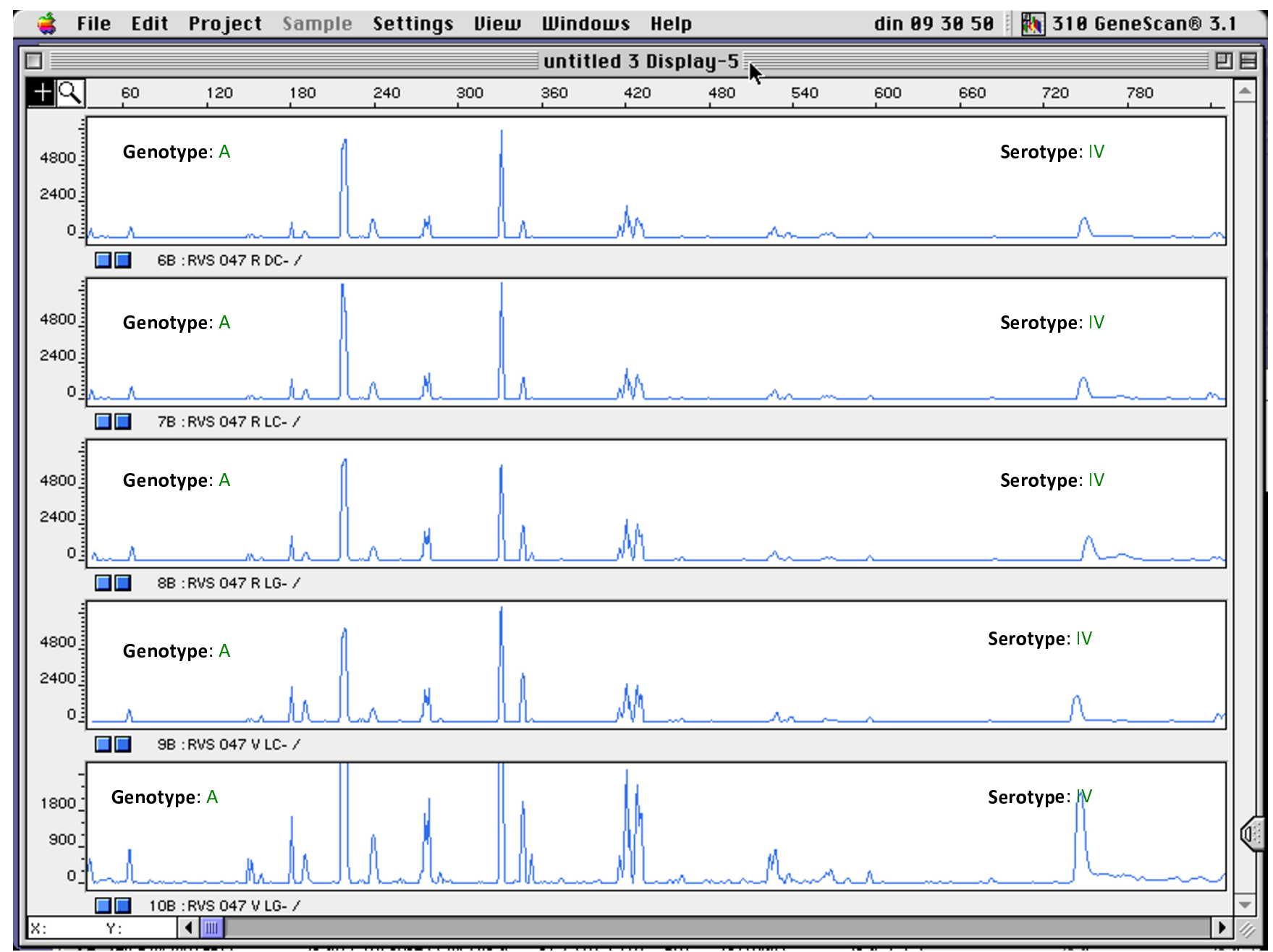

\section{Figure 2}

Fingerprints of different isolates of subject RVS047 with the same genotype and the same serotype. $x$-axis: length of amplified DNA fragments expressed in bps. y-axis: peak height (intensity of DNA-fragment).

\section{Antibiotic susceptibility testing}

GBS is considered homogenously susceptible to penicilline and amoxicillin. In case of allergy, second choice antibiotics are clindamycin or erythromycin. According to CLSI erythromycine can be tested with a simple disk test, although this is not done in our routine laboratory. Here we checked 40 isolates from 8 patients and found 26 isolates to be susceptible to both clindamycine and erythromycine, 3 to be clindamycine resistant and 11 to be resistant to both antibiotics. The susceptibility pattern of all strains was homogeneous for six subjects, despite genotypic differences among the isolates, whereas two subjects carried clindamycin resistant strains besides isolates susceptible to both antibiotics.

\section{Discussion}

Sensitivity and specificity of different culture techniques for the detection of GBS

In our study, only the combination of Lim broth and subculture on Granada agar enabled detection of all carriers, whereas direct inoculation onto Columbia CNA agar achieved a sensitivity of $40 \%$ and subculture of the Lim broth onto Columbia CNA agar detected $81 \%$ of the carriers.

Gil et al. [33] showed that in different studies the sensitivity of Granada agar ranged from 88.5 to $91.1 \%$, that of Columbia CNA agar from 83.9 to $94.3 \%$ and that of Lim broth (to which 5\% horse serum was added) was 63.5\% when subcultured on Granada agar and $75 \%$ when subcultured on Columbia CNA agar. Bosch-Mestres et al. [34] showed that the use of direct inoculation onto Granada 


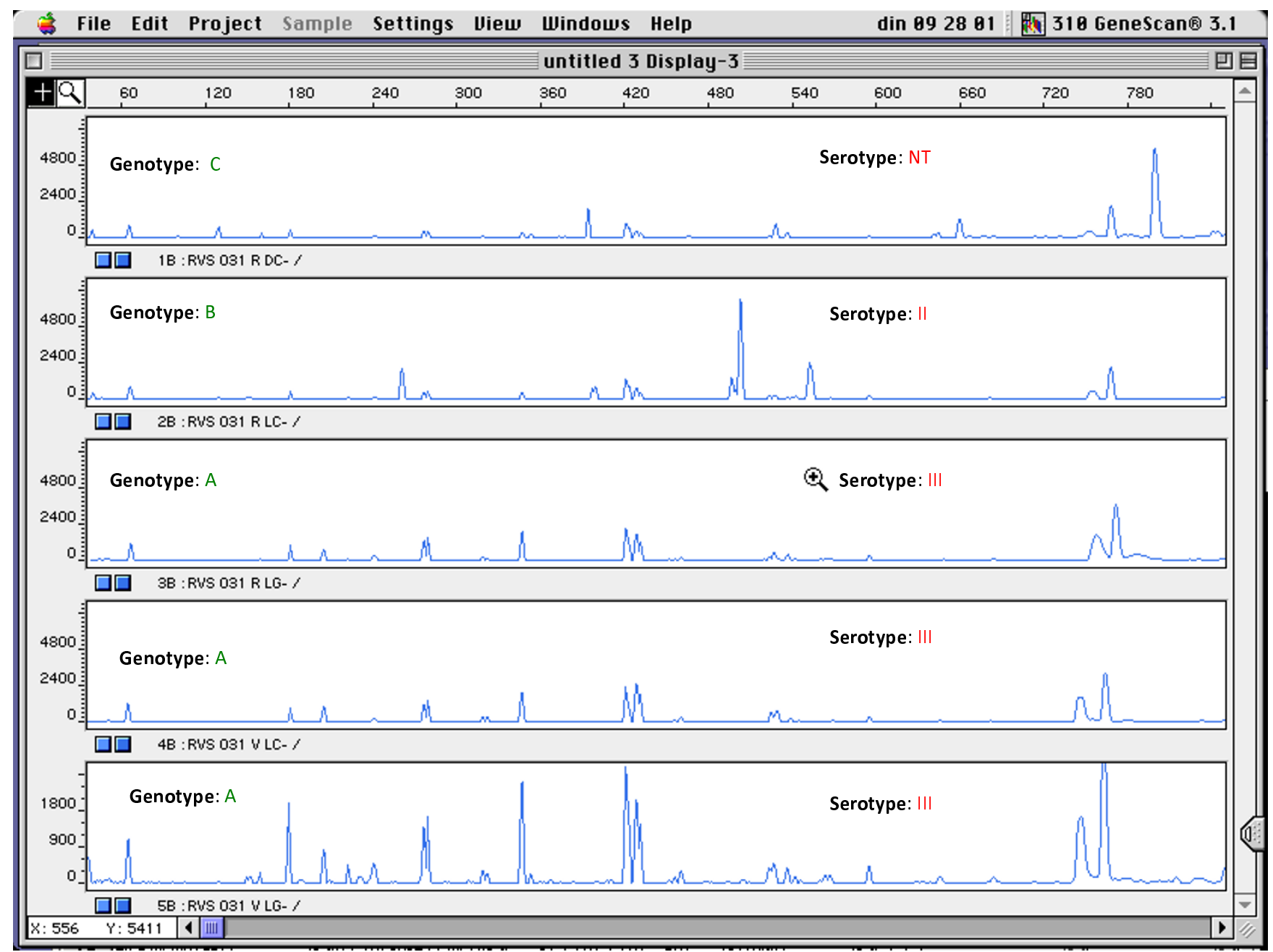

\section{Figure 3}

Fingerprints of different isolates of subject RVS03 I with different genotypes and different serotypes. X-axis: length of amplified DNA fragments expressed in bps. $y$-axis: peak height (intensity of DNA-fragment).

agar allowed fast detection for about $87 \%$ of carriers, where as the combination of Todd-Hewitt broth and subculture on Granada agar or Columbia CNA agar allowed detection of more than $99 \%$ of GBS carriers. Elsayed et al. [35] reported 79\% sensitivity for direct inoculation onto Columbia CNA agar and incubation during 48 hours compared to $100 \%$ sensitivity for Lim broth with subculture on blood agar. It can be concluded from this study and others that the combination of broth enrichment (Todd-Hewitt or LIM broth) with subculture on solid medium, yields higher sensitivity than direct inoculation onto solid media.

Although no definite conclusions can be drawn with regard to the sensitivity of the different solid media, Granada agar has the advantage that it makes possible to provide overnight results by visual inspection of the presence of red orange colonies, that are produced exclusively by GBS. The red orange colonies are easily observed, even when few colonies are present or when GBS is mixed with other microorganisms, which are mainly other streptococci [33] . The colonies are so characteristic and unique that identification by antigen detection or the CAMP test is unnecessary. In this study, all red orange colonies were CAMP positive (data not shown). Claeys et al. [36] missed only two CAMP positive isolates on a total of 310 tested, which were not red orange pigmented on Granada. Blanckaert et al. [37] used a combination of Granada and Columbia blood agar for GBS screening and demonstrated that $6 \%$ of the samples positive for GBS on Columbia blood agar lacked red orange colonies on Granada agar. Notably, Granada agar does not detect non-pigmented isolates, and on blood-agar these non-hemolytic isolates are difficult to detect as well. As a result of that, 
non hemolytic, nonpigmented strains may have been missed. In conclusion, in our hands, the use of combination of Lim broth and subculture on Granada agar provided high sensitivity and specificity for detecting GBS in vaginal and rectal swabs from pregnant women.

\section{Epidemiology}

The high prevalence of S. agalactiae colonization, i.e. $24 \%$, as established in this study, is in accordance with results from other European studies that report colonization rates between $10 \%$ and 36\% [38-43]. Thinkhamrop et al. [44] reported a prevalence of 7.1\% (Myanmar) to $19.1 \%$ (Philadelphia), using Lim broth culture. Toresani et al. [9] found a prevalence of only 3.2\% among 531 Argentinan pregnant women. Brimil et al. [38] showed equal carrier rates of $16 \%$ for GBS among pregnant and nonpregnant women and, based on the prevalence of GBS carriage, these authors concluded that strict adherence to the guidelines for prevention of GBS neonatal infection results in peripartal antibiotic prophylaxis in up to $20 \%$ of all deliveries.

Our data, are also in correspondence with other results on GBS prevalence in our country. Rectovaginal colonization with group B streptococci in Belgium is 13-25\%. These data are based on different studies carried out by the Belgian reference laboratory for GBS in collaboration with the section of epidemiology of the Scientific Institute for Public Health (ISP-WIV, Brussels) [45]. For example, Blanckaert et al. [37] compared the results of GBS screening on Granada agar with those obtained using standard Columbia blood agar at two participating centers in Belgium. They reported GBS-positive culture results of 10$30 \%$ of pregnant women. The Flemish Study Centre for Perinatal Epidemiology evaluated GBS prevalence in Flanders and found an average colonization rate of $16 \%$ among Flemish pregnant women [46].

Manning et al. [41] found that the prevalence of GBS colonization was equally high among 241 women (34\%) and 211 men (20\%) living in a college dormitory. Sexually experienced subjects had twice the colonization rates of sexually inexperienced participants. Van der Mee-Marquet et al. [47] reported that the prevalence of carriage was $27 \%$ in women and $32 \%$ in men. The major positive body site was the genital tract $23 \%$ in women and $21 \%$ in men) and skin, throats, and anal margins were also positive in $2 \%, 4 \%$, and $14 \%$, respectively.

\section{Comparison between vaginal and rectal carriage}

Brimil et al. [38] reported that for a total of 34 GBS positive pregnant women, 32\% carried GBS only vaginal, 24\% only rectal and $44 \%$ both rectal and vaginal, which compares well with our results, i.e. resp. $24 \%, 22 \%$ and 53\%.

\section{Serotypic and genotypic diversity among GBS isolates}

We studied the rectal and vaginal colonization with GBS of pregnant women attending the Ghent University hospital (Belgium) and the serotypic and genotypic diversity among the GBS isolates. Strong genotypic and serotypic heterogeneity was observed between women and for individual women, e.g., we found a total of 66 genotypes among 118 isolates (from 32 women), of which 4 women had up to 4 different genotypes in total (rectal + vaginal) and 14 women had up to 2 different genotypes vaginally.

Manning et al. [48] genotyped GBS isolates from vaginalrectal swabs of women at two visits and documented a turnover in $8.3 \%$ of 126 women colonized both at 35-37 weeks of gestation and 6 weeks after delivery. Unfortunately, only one isolate was genotyped per visit. Taking into consideration the genotypic diversity per subject, as observed in our study, a turnover of $8.3 \%$ might be an overestimation. When the same subject, carrying e.g. genotypes a, b and c, is sampled at two different moments, and whereby on each occasion only one colony is picked, the detection of a different genotype may be interpreted as turn over, but it may be that a genotype a strain has picked at the first visit but a genotype b or $c$ strain at the second visit.

Moreover, their conclusion that some clones are more likely to be lost should be interpreted with care, since their apparent disappearance might be explained by the presence of these clones in relatively lower numbers (compared to other clones), which reduces their chance of being picked at two separate occasions. To our knowledge, only one group studied genotypic diversity within individual women, by genotyping 15 randomly picked isolates for each of 30 women, albeit from mixed vaginalrectal specimens [12]. In opposition to our results, these authors found a high degree of genotypic and serotypic homogeneity, i.e. for 29 of 30 women, all 15 isolates from each woman had the same serotype, and for 27 of 30 women, all 15 isolates had the same chromosomal SmaIDNA restriction digest fingerprint. For the three women with different PFGE types, one had three different genotypes and two different serotypes. Another PFGE based study reported high stability of the GBS type for each woman, followed up to two years [40]. In accordance with our results, these authors found 30 different GBS isolates among 32 women, with only two women carrying isolates with the same genotype.

The high level of heterogeneity established in our study, compared to other studies, may be due to the different culture media that were used and to the use of separate swabs for sampling vagina and rectum for each individual woman. We found that strains of the same serotype recovered from different women were heterogeneous in DNA 
profiles. In accordance, SmaI-restriction digestion of chromosomal DNA and PFGE revealed high genotypic heterogeneity among both Zimbabwean serotype III and serotype V isolates [16], another study also reported different SmaI restriction types within serotypes II and V [12], and Fasola et al. [14] and Savoia et al. [49] showed that several genotypic lineages are present within the different serotypes.

Serotype switching is believed to occur within genotypic lineages $[7,24,25]$, presumably by horizontal transfer of genes of the cps locus, i.e. of genes encoding the GBS capsular polysaccharide structure [50], and may be an explanation for our observation of the presence of two isolates in two different women with the same genotype, but with a different serotype.

Although MLST has become the standard method to study the population structure of GBS $[22,24]$, more rapid and less expensive and laborious methods remain useful for carrying out single centre studies. We used RAPD-analysis in combination with high resolution capillary electrophoresis, which also makes possible immediate digitization of the fingerprints. Chatellier et al. [51] found that the simplest typing scheme of $S$. agalactiae was obtained by the combination of RAPD typing and serotyping (discriminatory index 0.97). Zhang et al. [20] found congruence between RAPD analysis and serotyping, on a limited number of strains. The findings of Toresani et al. [9], who found a total 16 RAPD profiles among 21 GBS isolates, from 17 women, and of Chatellier et al. [51], who identified 71 RAPD types among 54 unrelated $S$. agalactiae strains isolated from cerebrospinal fluid samples from neonates, point to the same genotypic diversity as observed in our study.

\section{General serotype distribution}

The capsule of $S$. agalactiae has long been recognized as one of the most important virulence factors. Variations of the capsular polysaccharide structure allow the antigenic distinction of 13 different $S$. agalactiae serotypes, of which 9 are of clinical importance (Ia, Ib, II-VIII). Studies from the US and Europe show that the serotypes Ia, II, III, and $\mathrm{V}$ are found in $80-90 \%$ of all clinical isolates $[4,48]$.

Serotype distribution among GBS isolates from pregnant women in our study was compared with that reported by others. Several studies indicate that serotype III is globally the most prevalent serotype, e.g. $29.2 \%$ of Israelian isolates [7], 28\% of German isolates [38], 24.3\% of Swedish isolates [39] and 33.2\% of Czech isolates [42]. In accordance, we observed a frequency of $20.8 \%$ for serotype III isolates in our study, as the most frequent serotype.

\section{Antibiotic susceptibility}

The finding that two out of 8 women carried isolates with different susceptibility to clindamycin indicates that when testing susceptibility for clindamycin several colonies should be tested, since colonies with different susceptibility may be simultaneously present.

\section{Conclusion}

In summary, our study, including 150 pregnant women, confirmed the European prevalence of around 20\% of GBS among pregnant women and the predominance of serotypes III and V among these women, but we established a higher genotypic diversity per individual than other studies, with up to four different genotypes among a maximum of 6 isolates per individual picked. Still, 18 of the 19 women with GBS from both rectum and vagina had at least one isolate from each sampling site with the same genotype. In our hands, the combination of Lim broth and subculture on Granada medium provided higher sensitivity than direct culture on Columbia CNA or Lim broth and subculture on Columbia CNA for GBS detection from vaginal and rectal swabs from pregnant women.

\section{Competing interests}

The authors declare that they have no competing interests.

\section{Authors' contributions}

NAE, RV, GC and MV participated in the development of the study design, the analysis of the study samples, the collection, analysis and interpretation of the data, and in the writing of the report. IT and MT participated in the development of the study design, the collection of the study samples, the collection, analysis and interpretation of the data, and in the writing of the report. BS and EDB participated in the analysis of the study samples and interpretation of the data. All authors read and approved the final manuscript.

\section{Acknowledgements}

Nabil Abdullah El Aila is indebted for a PhD Research funded by BOF-DOS of the University of Ghent-Belgium. BOF-DOS was not involved in the development of the study design, the collection, analysis, and interpretation of the data, in the writing of the report nor in the decision to submit the paper for publication.

\section{References}

I. Boyer KM, Gotoff SP: Strategies for chemoprophylaxis of GBS early-onset infections. Antibiot Chemother 1985, 35:267-280.

2. Schuchat A, Wenger JD: Epidemiology of group B streptococcal disease. Risk factors, prevention strategies, and vaccine development. Epidemiol Rev 1994, I 6(2):374-402.

3. Benson KD, Luchansky JB, Elliott JA, Degnan AJ, Willenberg HJ, Thornbery JM, Kay $\mathrm{HH}$ : Pulsed-field fingerprinting of vaginal group B streptococcus in pregnancy. Obstet Gynecol 2002, 100(3):545-55I.

4. Hickman ME, Rench MA, Ferrieri P, Baker CJ: Changing epidemiology of group B streptococcal colonization. Pediatrics 1999, 104(2 Pt I):203-209. 
5. Glantz JC, Kedley KE: Concepts and controversies in the management of group B streptococcus during pregnancy. Birth 1998, 25(I):45-53.

6. Artz LA, Kempf VA, Autenrieth IB: Rapid screening for Streptococcus agalactiae in vaginal specimens of pregnant women by fluorescent in situ hybridization. J Clin Microbiol 2003 4I(5):2I70-2I73.

7. Bisharat N, Jones N, Marchaim D, Block C, Harding RM, Yagupsky P, Peto T, Crook DW: Population structure of group B streptococcus from a low-incidence region for invasive neonatal disease. Microbiology 2005, I 5 I (Pt 6): | 1875- I88I.

8. Schuchat A: Epidemiology of group B streptococcal disease in the United States: shifting paradigms. Clin Microbiol Rev 1998 I I (3):497-5I3.

9. Toresani I, Limansky A, Bogado I, Guardati MC, Viale A, Sutich EG Phenotypic and genotypic study of Streptococcus agalactiae in vagina of pregnant women in Argentina. Medicina (B Aires) 200I, 6 I (3):295-300.

10. Blumberg HM, Stephens DS, Licitra C, Pigott N, Facklam R, Swaminathan B, Wachsmuth IK: Molecular epidemiology of group B streptococcal infections: use of restriction endonuclease analysis of chromosomal DNA and DNA restriction fragment length polymorphisms of ribosomal RNA genes (ribotyping). J Infect Dis 1992, I 66(3):574-579.

II. Huet H, Martin C, Geslin P, Grimont F, Quentin R: Ribotyping of Streptococcus agalactiae strains isolated from vaginas of asymptomatic women. Res Microbiol I993, I44(6):457-465.

12. Perez-Ruiz M, Rodriguez-Granger JM, Bautista-Marin MF, RomeroNoguera J, Rosa-Fraile M: Genetic diversity of Streptococcus agalactiae strains colonizing the same pregnant woman. Epidemiol Infect 2004, I 32(2):375-378.

13. Martins ER, Pessanha MA, Ramirez M, Melo-Cristino J: Analysis of group $B$ streptococcal isolates from infants and pregnant women in Portugal revealing two lineages with enhanced invasiveness. J Clin Microbiol 2007, 45( I 0):3224-3229.

14. Fasola E, Livdahl C, Ferrieri P: Molecular analysis of multiple isolates of the major serotypes of group B streptococci. J Clin Microbiol I993, 3 I (I 0):2616-2620.

15. Gordillo ME, Singh KV, Baker C], Murray BE: Typing of group B streptococci: comparison of pulsed-field gel electrophoresis and conventional electrophoresis. I Clin Microbiol 1993, 3 I(6): | $430-1434$

16. Moyo SR, Maeland JA, Bergh K: Typing of human isolates of Streptococcus agalactiae (group B streptococcus, GBS) strains from Zimbabwe. I Med Microbiol 2002, 5 I (7):595-600.

17. Rolland K, Marois C, Siquier V, Cattier B, Quentin R: Genetic features of Streptococcus agalactiae strains causing severe neonatal infections, as revealed by pulsed-field gel electrophoresis and hylB gene analysis. J Clin Microbiol 1999, 37(6): $1892-1898$.

18. Quentin R, Huet H, Wang FS, Geslin P, Goudeau A, Selander RK Characterization of Streptococcus agalactiae strains by multilocus enzyme genotype and serotype: identification of multiple virulent clone families that cause invasive neonatal disease. J Clin Microbiol I995, 33( I 0):2576-258I.

19. Limansky AS, Sutich EG, Guardati MC, Toresani IE, Viale AM: Genomic diversity among Streptococcus agalactiae isolates detected by a degenerate oligonucleotide-primed amplification assay. I Infect Dis 1998, I77(5): | 308-I3|3.

20. Zhang GW, Kotiw M, Daggard G: A RAPD-PCR genotyping assay which correlates with serotypes of group $B$ streptococci. Lett Appl Microbiol 2002, 35(3):247-250.

21. Manning SD, Lacher DW, Davies HD, Foxman B, Whittam TS: DNA polymorphism and molecular subtyping of the capsular gene cluster of group B streptococcus. J Clin Microbiol 2005, 43(12):6I13-6116.

22. Bohnsack JF, Whiting A, Gottschalk M, Dunn DM, Weiss R, Azimi PH, Philips JB 3rd, Weisman LE, Rhoads GG, Lin FY: Population structure of invasive and colonizing strains of Streptococcus agalactiae from neonates of six U.S. Academic Centers from I995 to 1999. J Clin Microbiol 2008, 46(4): |285-I29|

23. Davies HD, Jones N, Whittam TS, Elsayed S, Bisharat N, Baker Cl: Multilocus sequence typing of serotype III group B streptococcus and correlation with pathogenic potential. J Infect Dis 2004, I 89(6): 1097-II02.
24. Luan SL, Granlund M, Sellin M, Lagergard T, Spratt BG, Norgren M: Multilocus sequence typing of Swedish invasive group $B$ streptococcus isolates indicates a neonatally associated genetic lineage and capsule switching. J Clin Microbiol 2005, 43(8):3727-3733

25. Jones N, Bohnsack JF, Takahashi S, Oliver KA, Chan MS, Kunst F, Glaser $\mathrm{P}$, Rusniok C, Crook DW, Harding RM, et al:: Multilocus sequence typing system for group B streptococcus. J Clin Microbiol 2003, 4 I (6):2530-2536.

26. Jones DE, Kanarek KS, Lim DV: Group B streptococcal colonization patterns in mothers and their infants. J Clin Microbiol 1984 , 20(3):438-440.

27. Rosa-Fraile M, Sampedro A, Rodriguez-Granger J, Garcia-Pena ML, Ruiz-Bravo A, Haidour A: Pigment production by Streptococcus agalactiae in quasi-defined media. Appl Environ Microbiol 200I, 67(I):473-474

28. Baele M, Storms V, Haesebrouck F, Devriese LA, Gillis M, Verschraegen $G$, de Baere T, Vaneechoutte M: Application and evaluation of the interlaboratory reproducibility of tRNA intergenic length polymorphism analysis (tDNA-PCR) for identification of Streptococcus species. J Clin Microbiol 200 I, 39(4): I436-I 442.

29. Van Daele S, Vaneechoutte M, De Boeck K, Knoop C, Malfroot A, Lebecque P, Leclercq-Foucart J, Van Schil L, Desager K, De Baets F: Survey of Pseudomonas aeruginosa genotypes in colonised cystic fibrosis patients. Eur Respir J 2006, 28(4):740-747.

30. Baele M, Baele P, Vaneechoutte M, Storms V, Butaye P, Devriese LA Verschraegen G, Gillis M, Haesebrouck F: Application of tRNA intergenic spacer PCR for identification of Enterococcus species. I Clin Microbiol 2000, 38( I I):420 I-4207.

31. Antonio MA, Hawes SE, Hillier SL: The identification of vaginal Lactobacillus species and the demographic and microbiologic characteristics of women colonized by these species. Infect Dis 1999, I80(6): 1950-1956.

32. Antonio MA, Rabe LK, Hillier SL: Colonization of the rectum by Lactobacillus species and decreased risk of bacterial vaginosis. J Infect Dis 2005, I 92(3):394-398.

33. Gil EG, Rodriguez MC, Bartolome R, Berjano B, Cabero L, Andreu A Evaluation of the Granada agar plate for detection of vaginal and rectal group B streptococci in pregnant women. Journal of Clinical Microbiology 1999, 37(8):2648-265।.

34. Bosch-Mestres J, Martin-Fernandez RM, Jimenez de Anta-Losada MT: [Comparative study of three culture media for detecting group B Streptococcus colonization in pregnant women]. Enferm Infecc Microbiol Clin 2003, 2 I (7):346-349.

35. Elsayed S, Gregson DB, Church DL: Comparison of direct selective versus nonselective agar media plus LIM broth enrichment for determination of group B streptococcus colonization status in pregnant women. Arch Pathol Lab Med 2003, I 27(6):718-720

36. Claeys G, Verschraegen G, Temmerman M: Modified Granada Agar Medium for the detection of group B Streptococcus carriage in pregnant women. Clin Microbiol Infect 200I, 7(1):22-24.

37. Blanckaert H, Frans J, Bosteels J, Hanssens M, Verhaegen J: Optimisation of prenatal group B streptococcal screening. Eur J Clin Microbiol Infect Dis 2003, 22(10):619-621.

38. Brimil N, Barthell E, Heindrichs U, Kuhn M, Lutticken R, Spellerberg $\mathrm{B}$ : Epidemiology of Streptococcus agalactiae colonization in Germany. Int J Med Microbiol 2006, 296(I):39-44.

39. Hakansson $S$, Axemo P, Bremme K, Bryngelsson AL, Wallin MC, Ekstrom CM, Granlund M, Jacobsson B, Kallen K, Spetz E, et al: Group B streptococcal carriage in Sweden: a national study on risk factors for mother and infant colonisation. Acta Obstet Gynecol Scand 2008, 87( (I):50-58.

40. Hansen SM, Uldbjerg N, Kilian M, Sorensen UB: Dynamics of Streptococcus agalactiae colonization in women during and after pregnancy and in their infants. I Clin Microbiol 2004, 42(I):83-89.

4l. Manning SD, Neighbors K, Tallman PA, Gillespie B, Marrs CF, Borchardt SM, Baker CJ, Pearlman MD, Foxman B: Prevalence of group $B$ streptococcus colonization and potential for transmission by casual contact in healthy young men and women. Clin Infect Dis 2004, 39(3):380-388.

42. Motlova J, Strakova L, Urbaskova P, Sak P, Sever T: Vaginal \& rectal carriage of Streptococcus agalactiae in the Czech Republic: 
incidence, serotypes distribution \& susceptibility to antibiotics. Indian J Med Res 2004, I I 9(Suppl):84-87.

43. Trijbels-Smeulders M, Gerards LJ, M PC, de Jong $P$, van Lingen RA, Adriaanse AH, de Jonge GA, Kollee LA: Epidemiology of neonatal group B streptococcal disease in The Netherlands 1997-98. Paediatr Perinat Epidemiol 2002, 16(4):334-34l.

44. Thinkhamrop J, Limpongsanurak S, Festin MR, Daly S, Schuchat A, Lumbiganon P, Zell E, Chipato T, Win AA, Perilla MJ, et al.: Infections in international pregnancy study: performance of the optical immunoassay test for detection of group B streptococcus. J Clin Microbiol 2003, 4 I ( I I):5288-5290.

45. Prevention of perinatal group B Streptococcal infections Guidelines from the Belgian Health Council. 2003 (SHC.772I) [http:// www.health.fgov.be/CSH HGR/English/Brochures/ GBS EN2003.pdf]

46. Perinatal activity in Flanders Study Centre for Perinatal Epidemiology (SPE) Flanders. Annual Report 2006 [http://www.zorg-en-gezond heid.be/uploadedFiles/NLsite/Cijfers/Gezondheidsindicatoren/ Ziekte en gezondheid/Geboorte en bevalling/SPE 2006.pdf].

47. Mee-Marquet $\mathrm{N}$ van der, Fourny L, Arnault L, Domelier AS, Salloum $M$, Lartigue MF, Quentin R: Molecular characterization of human-colonizing Streptococcus agalactiae strains isolated from throat, skin, anal margin, and genital body sites. J Clin Microbiol 2008, 46(9):2906-29I I.

48. Manning SD, Schaeffer KE, Springman AC, Lehotzky E, Lewis MA, Ouellette LM, Wu G, Moorer GM, Whittam TS, Davies HD: Genetic diversity and antimicrobial resistance in group $B$ streptococcus colonizing young, nonpregnant women. Clin Infect Dis 2008, 47(3):388-390.

49. Savoia D, Gottimer C, Crocilla C, Zucca M: Streptococcus agalactiae in pregnant women: phenotypic and genotypic characters. J Infect 2008, 56(2): $120-125$

50. Cieslewicz MJ, Chaffin D, Glusman G, Kasper D, Madan A, Rodrigues $S$, Fahey J, Wessels MR, Rubens CE: Structural and genetic diversity of group B streptococcus capsular polysaccharides. Infect Immun 2005, 73(5):3096-3103.

5I. Chatellier S, Ramanantsoa C, Harriau P, Rolland K, Rosenau A, Quentin R: Characterization of Streptococcus agalactiae strains by randomly amplified polymorphic DNA analysis. J Clin Microbiol 1997, 35(10):2573-2579.

\section{Pre-publication history}

The pre-publication history for this paper can be accessed here:

http://www.biomedcentral.com/1471-2334/9/153/pre

pub
Publish with Bio Med Central and every scientist can read your work free of charge

"BioMed Central will be the most significant development for disseminating the results of biomedical research in our lifetime. "

Sir Paul Nurse, Cancer Research UK

Your research papers will be:

- available free of charge to the entire biomedical community

- peer reviewed and published immediately upon acceptance

- cited in PubMed and archived on PubMed Central

- yours - you keep the copyright

Submit your manuscript here:

http://www.biomedcentral.com/info/publishing_adv.asp
BioMedcentral 